\title{
Canine Pancreatic Carcinoma
}

National Cancer Institute

\section{Source}

National Cancer Institute. Canine Pancreatic Carcinoma. NCI Thesaurus. Code C134944.

Pancreatic carcinoma that occurs in a dog. 